\title{
Dynamic recrystallisation can produce porosity in shear zones
}

\author{
James Gilgannon $^{1}$, Thomas Poulet ${ }^{2,3}$, Alfons Berger ${ }^{1}$, Auke Barnhoorn ${ }^{4}$, \\ Marco Herwegh ${ }^{1}$ \\ ${ }^{1}$ Institute of Geological Sciences, University of Bern, Baltzerstrasse 1+3, 3012 Bern, Switzerland \\ ${ }^{2}$ CSIRO Mineral Resources, Kensington, WA 6151, Australia \\ ${ }^{3}$ School of Minerals and Energy Resources Engineering, UNSW Sydney, NSW 2052, Australia \\ ${ }^{4}$ Department of Geoscience and Engineering, Delft University of Technology, Delft, The Netherlands
}

\section{Key Points:}

- Creep cavities emerge with grain-size reduction by sub-grain rotation recrystallisation.

- Porosity driven by creep can be opened and sustained at high confining pressures.

- There is a direct and spontaneous physical path for single phase rocks to transition to polyphase rocks during deformation.

Corresponding author: James Gilgannon, james.gilgannon@geo.unibe.ch 


\begin{abstract}
Creep cavities are increasingly recognised as an important syn-kinematic feature of shear zones but much about this porosity needs investigation. Largely, observations of creep cavities are restricted to very fine grained mature ultramylonites and it is unclear when they developed during deformation. Specifically, a question that needs testing is; should grain-size reduction during deformation produce creep cavities? To this end, we have reanalysed the microstructure of a large shear strain laboratory experiment that captures grain-size change by dynamic recrystallisation during mylonitisation. We find that the experiment does contain creep cavities. Using a combination of scanning electron microscopy and spatial point statistics, we show that creep cavities emerge with, and because of, sub-grain rotation recrystallisation during ultramylonite formation. As dynamic recrystallisation is ubiquitous in natural shear zones, this observation has important implications for the interpretation of concepts such as the Goetze criterion, palaeopiezometery and phase mixing.
\end{abstract}

\title{
Plain Language Summary
}

At great depths inside the Earth, rocks called mylonites slowly deform and accommodate tectonic forces. Generally, these rocks are considered to have no porosity because the pressure they experience is very large. However, it is frequently documented that these mylonites focus the transport of mass, both fluid and solid, through the Crust. This implies that mylonites host a permeable porosity. To better understand this paradox, we reanalysed an old laboratory experiment that documented the formation of a mylonite. We showed that a porosity, known as creep cavities, forms synchronously with the mylonite. This is an important experimental finding because it suggests that creep cavities are a fundamental feature of mylonites. Our results showcase a rare snapshot into the dynamics of rocks important for tectonics and advance larger questions about their transport properties.

\section{Introduction}

Shear zones have long been recognised as important because they mechanically release tectonic stresses and focus the transport of mass, both fluid and solid, through the Earth. Recently, it has been argued that mature fine grained polymineralic shear zones host a permeable porosity known as creep cavities (Dimanov et al., 2007; Fusseis et al., 2009 ) and that the processes of creep cavitation facilitates the migration of fluid and aids dissolution and precipitation processes (Herwegh \& Jenni, 2001). This new paradigm has cast the discussion of deep fine grained fault rocks away from classical kinematics and into a new more dynamic light. Field and experimental studies on creep cavities have provided new context to the long discussed problems of phase mixing in ultramylonites (Dimanov et al., 2007; Menegon et al., 2015; Précigout \& Stünitz, 2016; Gilgannon et al., 2017; Lopez-Sanchez \& Llana-Fúnez, 2018) and advection driven fluid and mass transfer in shear zones (Fusseis et al., 2009; Menegon et al., 2015; Précigout et al., 2017, 2019). Beyond this there are many questions that need to be addressed to correctly place creep cavities within the geological framework of large-scale shear zones.

First among these is what specific factors promote or inhibit creep cavity formation in rocks? A critical assumption in most of the work on creep cavities has been that a grain-size sensitive rheology is needed for their formation. For example, in natural shear zones microstructural evidence has been presented to argue that creep cavities emerge with the production of fine grained mixtures during symplectite reactions and the transition to a grain-size sensitive rheology (Ceccato et al., 2018). Addtionally, creep cavities have been interpreted to become active after fracture induced grain-size reduction of feldspar in granulite rocks (Menegon et al., 2013). This would seem to place a limit 
on the activity of creep cavitation and presents a test for its emergence. More generally, this could suggest that any syn-kinematic grain-size reducing process inside of a ductile shear zone has the potential to produce creep cavities.

Dynamic recrystallisation is a major grain-size reduction mechanism in shear zones and it is observed or interpreted for almost all of Earth's major constitutive minerals (for example: calcite (Ter Heege et al., 2002; Bestmann \& Prior, 2003); quartz (Hirth \& Tullis, 1992; Stipp et al., 2002); feldspar (Tullis \& Yund, 1985; Kruse et al., 2001); olivine (Lee et al., 2002; Michibayashi et al., 2006). As dynamic recrystallisation is ubiquitous in shear zones, any porosity produced as a consequence could play an important role in large-scale shear zone processes. Here we revisit confined experiments that documented the process of grain-size reduction by dynamic recrystallisation at high homologous temperatures for Carrara marble. We use these experiments to test the hypothesis that dynamic recrystallisation by sub-grain rotation should produce creep cavities. In a calculated representative microstructure, we show statistically that dynamic recrystallisation does indeed generate a syn-kinematic porosity and discuss some of the consequences of this new finding.

\section{Materials and Methods}

We revisit the Carrara Marble sample P0422 from the high shear strain torsion experiments of Barnhoorn et al. (2004) (fig. 1a). The sample was deformed to a shear strain $(\gamma)$ of 5 with a constant shear strain rate $\left(\dot{\gamma}=3 \times 10^{-4}\right)$ at a temperature of $1000 \mathrm{~K}$ and a confining pressure of $300 \mathrm{MPa}$ (Text S1). Specifically, this sample captures pervasive, but incomplete, microstructural change through dynamic recrystallisation by sub-grain rotation recrystallisation (fig. 1b). In addition to this we observe a previously unreported grain boundary porosity (fig. 1c and d). We utilise the window this sample provides into the deformation dynamics to evaluated any relationship between syn-kinematic pores and newly recrystallised grains.

We analyse a close to tangential cut from the cylindrical sample. This cut approximately corresponds to the XZ plane of finite strain and captures close to the maximum shear strain and shear strain rate of the deformed sample (Paterson \& Olgaard, 2000).

The main results of this contribution come from sample PO422 but we find supporting evidence for syn-kinematic grain boundary porosity in two more samples that have experienced both more shear strain and recrystallisation. The samples are PO274 $\left(\dot{\gamma}=3 \times 10^{-4}, \gamma=6.9\right)$ and PO303 $\left(\dot{\gamma}=1 \times 10^{-3}, \gamma=7.9\right)$. We have provided additional, more qualitative, information about these experiments along side our criteria for defining the porosity as syn-kinematic in Text S2.

\subsection{Defining a representative microstructure}

To meaningfully assess any relationships between microstructural components we calculated a 2D representative volume element (RVE). The RVE defines the minimum area required to capture any variation in the microstructure (cf. Akker et al., 2018). This is achieved by expanding the area of investigation until the feature of interest, in our case porosity, stops varying. We borrow this homogenisation approach from the calculation of material properties, like the elastic moduli, where the RVE provides a minimum sample size that can accurately describe the property (Hill, 1963; Regenauer-Lieb et al., 2014).

Using a large $(4.2 \times 3.8 \mathrm{~mm}$ on a scale of $1: 0.55 ; \mathrm{px}: \mu \mathrm{m})$ backscatter electron (BSE) mosaic (fig. 1a) segmented for porosity, the RVE was obtained by randomly generating a series of increasingly larger boxes across the sample and then calculating the porosity contained within (fig. 2a). This procedure was repeated 100 times to give statistically robust distributions for each box size. The change in standard deviation with box 
a)

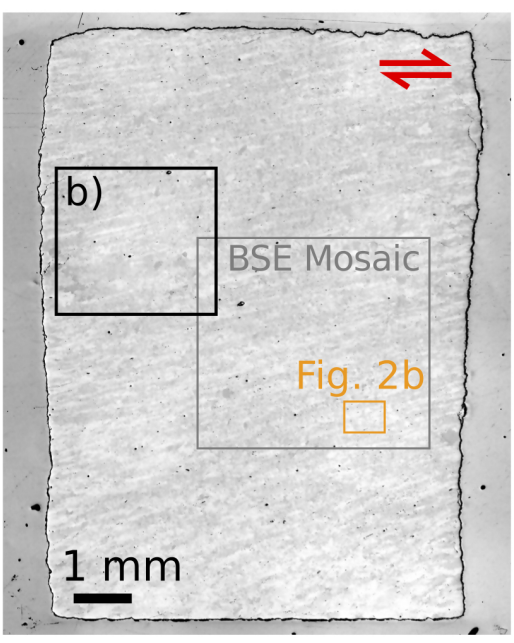

c)

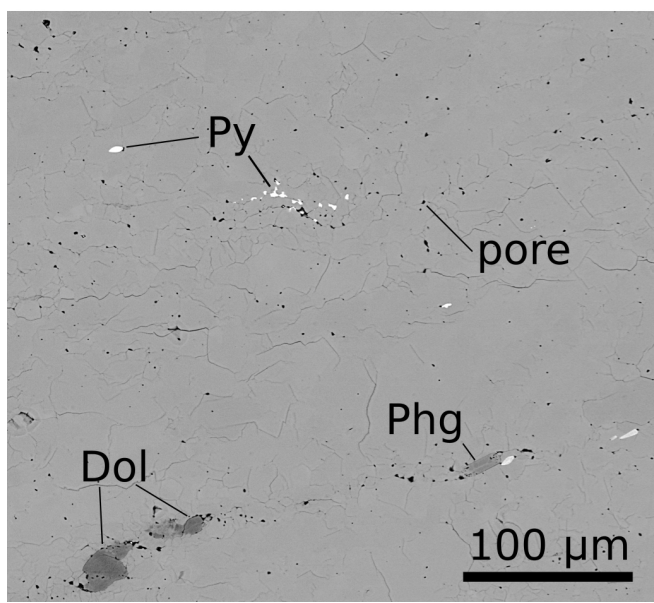

b)

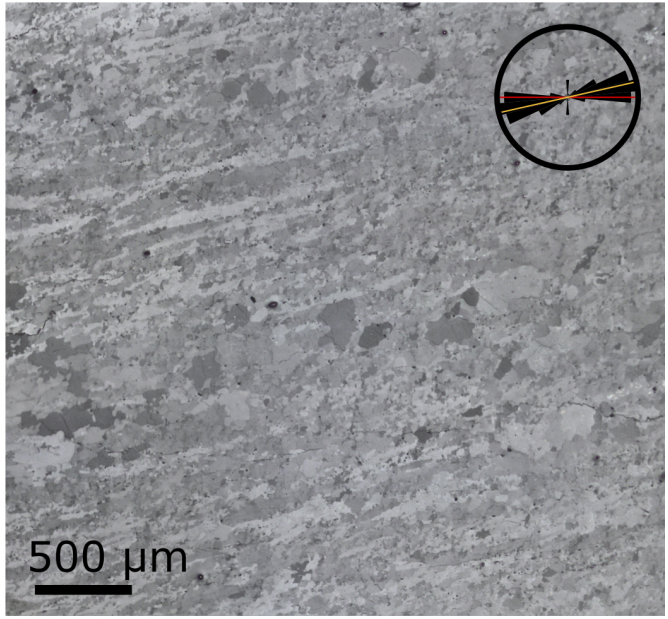

d)

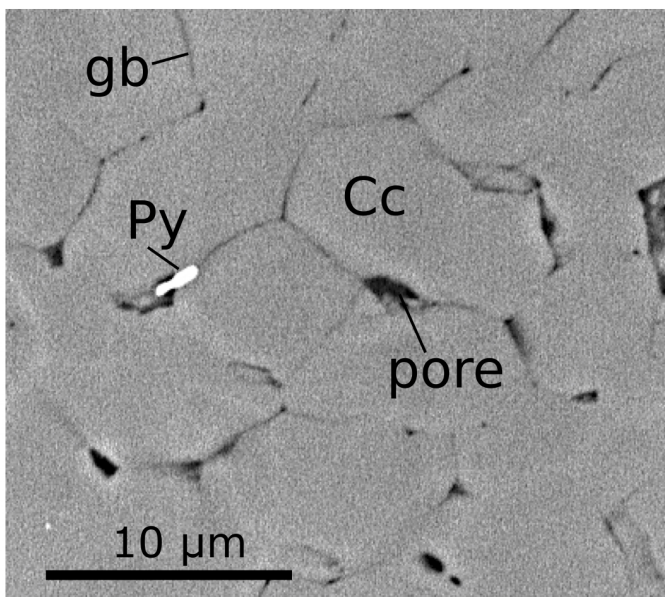

Figure 1. An overview of the investigated section and the details of its microstructures: a) shows a reflected light image of the cut section with the areas of analysis highlighted; b) is a reflected light image of the microstructure with an inset rose diagram of the long axis orientations of 83 phengite minerals. The red and orange lines in the rose diagram are the shear plane and the calculated angular shear for $\gamma=5$ (see Text S7); c) and d) are backscatter electron images that document the new observation of creep cavities in the experiment. (Py $=$ pyrite, $\mathrm{Dol}=$ dolomite, $\mathrm{Phg}=$ phengite, $\mathrm{Cc}=$ calcite, $\mathrm{gb}=$ grain boundary) 
a) RVE $>737 \mu \mathrm{m}$

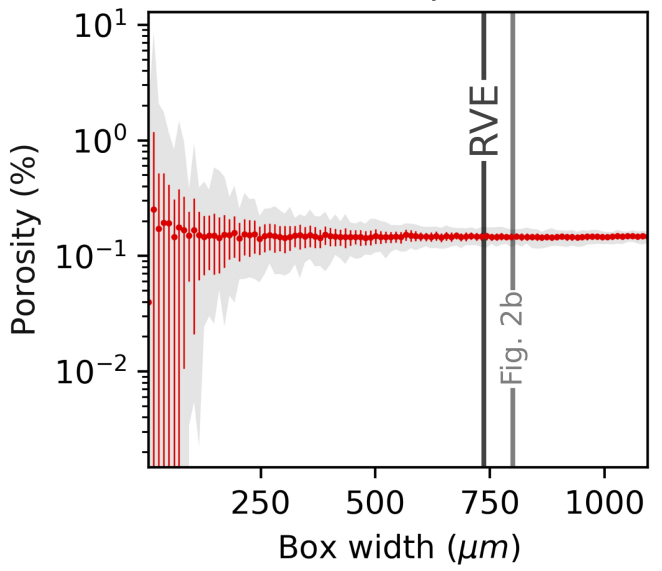

b) Rep. microstructure

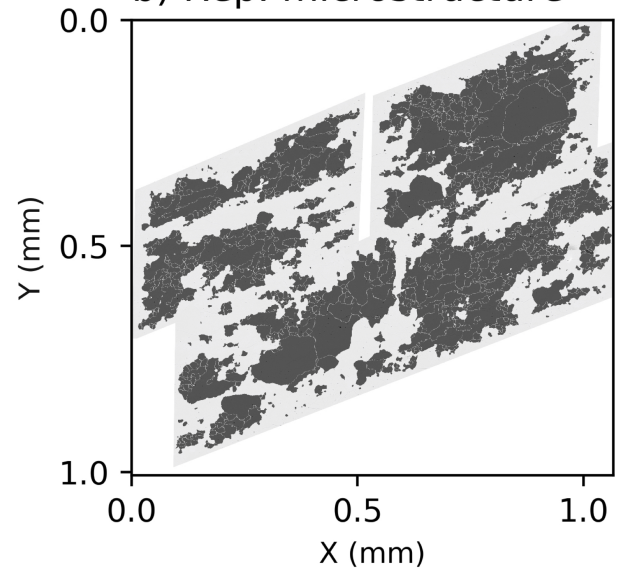

Figure 2. A visualisation of the calculated threshold for defining the representative microstructure (fig. 2a) and the mapped representative microstructure (fig. 2b) (for details see section 2.1). In figure $2 \mathrm{a}$ the red dot, red lines and the grey shaded area represent the mean, \pm 1 standard deviation of the distribution and the maximum/minimum envelope respectively. Figure $2 \mathrm{~b}$ shows the BSE and EBSD grain maps of the representative microstructure on top of one another.

size is used to determine the RVE because it best reflects a decrease in the variation of the calculation (Figure S1). For perspective, the area of the mosaic used for the RVE calculation is approximately equal to $19 \%$ of the area of the tangential cut shown in figure 1a. Once the minimum area needed was identified (fig. 2a), a set of electron backscatter diffraction (EBSD) maps and a local BSE map were made on a representative microstructure (fig. 2b).

Details about the acquisition and processing of data is reported in the supplement.

\subsection{Statistical analysis of pores and grains in space}

On this representative microstructure we employed spatial point statistics to test the spatial relationships between the observed porosity and different grain-size populations. Importantly, when this statistical information is combined with knowledge of the deformation path and active processes a causal model of pore formation can be formulated.

First, the spatial coincidence of the different data sets needed to be assured. To achieve this, the EBSD output rasters were all mapped to the BSE map in QGIS with the Georeferencer plugin. A thin plate spline transformation was used with a cubic spline resampling on a total of 623 tie points between maps (Table S1). This process simultaneously corrected for distortions in the tilted EBSD data and ensured the correct spatial positions of the data. Once corrected for distortion, the total area mapped by EBSD approximates to $650000 \mathrm{\mu m}^{2}$. In the context of the RVE calculation this value approximately equates to an equivalent square box of 800 x $800 \mu m$ (fig. 2a).

From this corrected data set we extracted the centroids of pores and grains. As we are interested in deformation induced changes in grain-size we chose to analyse two relevant grain subsets: newly recrystallised grains $(\leq 10 \mu \mathrm{m})$ and relic grains $(\geq 40 \mu \mathrm{m})$. 
For relic grains this corresponds to the smallest initial area-weighted grain-size reported for the Carrara Marble by Pieri, Burlini, et al. (2001). For new grains the limit is chosen to include the steady state grain-size reported by Barnhoorn et al. (2004) (6-10 $\mu \mathrm{m})$.

To these subsets we applied the uni and bivariant forms of the pair correlation function (Wiegand et al., 2009; Wiegand \& Moloney, 2014; Mitchell et al., 2015) in the software Programita (Wiegand \& Moloney, 2014). This spatial point analysis gives information about the pair distances between points and how these data pairs are related in space. More specifically, the pair correlation function describes how the true density function of the data compares to a density function of a spatially random model. Theoretically, this means that pair correlation function values of 1 report that the data is distributed randomly in space, greater than 1 highlight spatial clustering, while values less than 1 identify ordering, or anti-clustering. To account for the natural variation in real data 199 simulations of randomness were calculated and provide an envelop for spatially random data. The function is a non-cumulative statistic and is calculated for an expanding radius of a ring with a specific width (Figure S7). This provides information about the distances at which data points can 'see' other data points and if their relation is one of clustering, ordering or randomness.

For the parameters used in the analysis please refer to the supplementary information.

\section{Results}

\subsection{A general microstructural description}

In general, the sample clearly shows a microstructural change from the starting grainsize distribution (mean $=125 \mu \mathrm{m}$ (Barnhoorn et al., 2004)) to a new recrystallised grainsize distribution (mean $=6-10 \mu m$ (Barnhoorn et al., 2004)) (fig. 1). This change manifests itself at the section scale and produces a foliation (fig. 1a). Upon closer inspection it can be seen that the foliation is made up of elongated calcite crystals (fig. 1b). These elongated ribbon grains are plastically deformed and can be seen undergoing subgrain rotation recrystallisation to smaller grain-sizes (cf. Barnhoorn et al., 2004). Across the sample the secondary phases are well distributed, with phengite showing orientations that seem to track the foliation (see inset rose diagram in fig. 1b). The most striking feature in the sample is a conspicuous grain boundary porosity that can be qualitatively associated to regions of finer grain-sizes (fig. 1c and d). The porosity is syn-kinematic, a fact illustrated by the presence of precipitates forming in pores (fig. 1c and d), and we interpret them as creep cavities (please refer to Text S2 for further critera). We expect these creep cavities to be filled with a fluid-gas mixture developed early in the experiment from inital fluid inclusions and a $\mathrm{CO}_{2}$ partial pressure from decarbonation.

Three important microstructural elements are considered in the following: 1) relic grains (grains $\geq 40 \mu \mathrm{m}$ ); 2) newly recrystallised grains (grains $\leq 10 \mu \mathrm{m}$ );3) and creep cavities. The rest of the results will consider the relationship between these elements in a calculated representative microstructure.

\subsection{Defining a representative microstructure}

Using the method described in section 2.1, it was found that the minimum square box size needed to describe a $2 \mathrm{D}$ representative volume element (RVE) is $737 \times 737 \mu \mathrm{m}$ (fig. 2a).

The following results come from a series of analyses made on an area larger than the calculated RVE (fig. 2a and b). This area is presented in figure 2b. and shows a BSE map overlain by grain maps calculated from EBSD data. The grain-size distribution for the representative microstructure highlights that microstructural change has not yet come 
a)

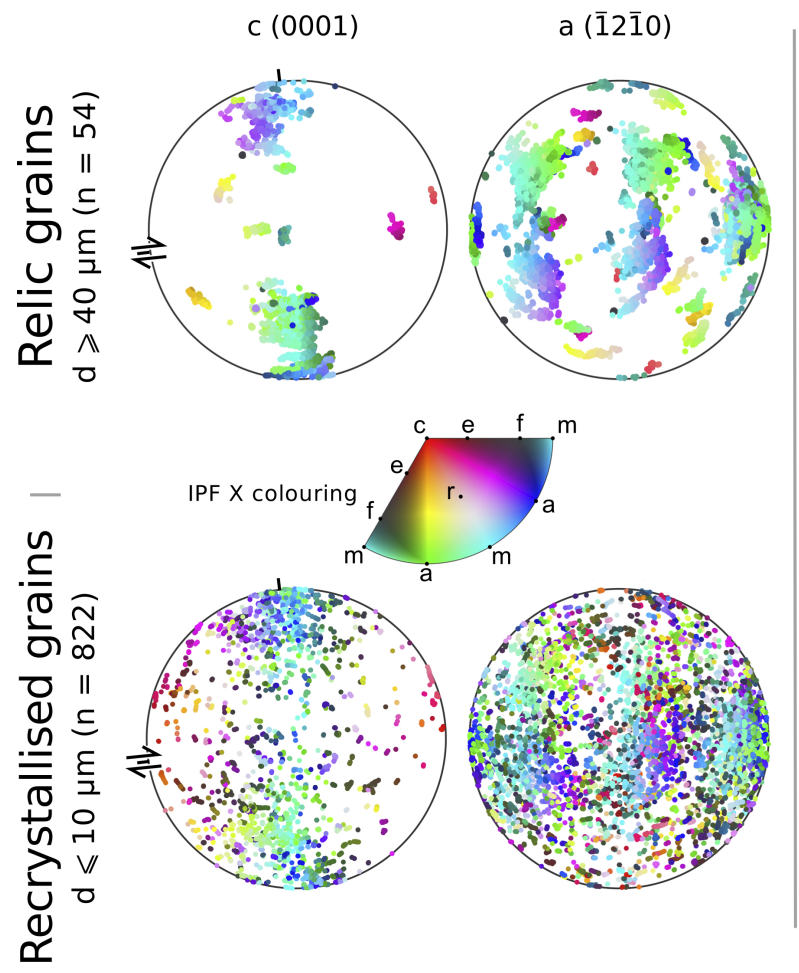

b)
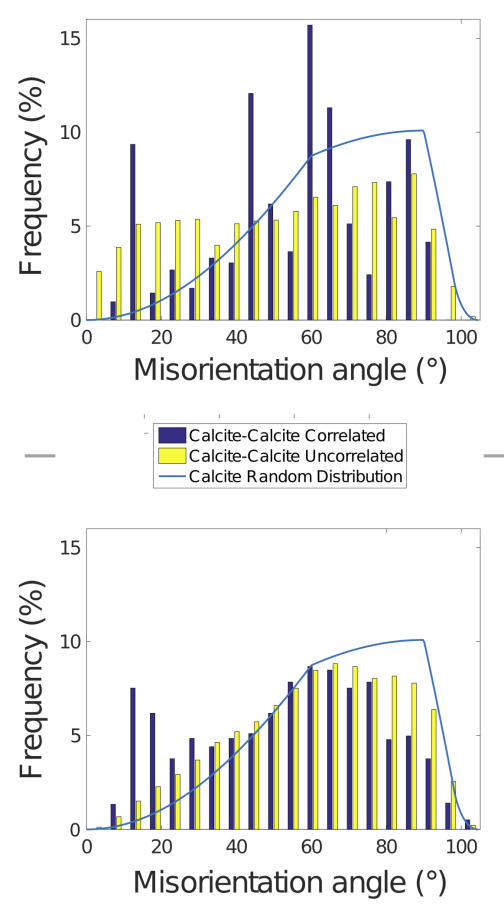

Figure 3. Visualisation of texture and orientations of the grain populations of interest. Figure 3 a shows the $c$ - and a-axis pole figures. 10000 random orientations are presented and coloured coded according to how their host grain's crystallography is aligned with the $\mathrm{X}$ direction of finite strain. Figure 3b shows complementary grain misorientation histograms for both grain subsets. No sub-grain data is considered.

to completion but is well developed (Figure S6). The number weighted histogram of figure S6 highlights the establishment of the peak identified by Barnhoorn et al. (2004) to represent the steady state recrystallised grain-size of $\approx 10 \mu \mathrm{m}$.

\subsection{A representative texture}

Relic grains show a clear crystallographic preferred orientation (CPO). There are two major clusters in the c-axis pole figure (fig. 3a). This is reinforced by the inverse pole figure colouring which highlights the same two dominant grain orientation sets found by Barnhoorn et al. (2004) and Pieri, Kunze, et al. (2001). The misorientation histogram for relic grains shows a distribution that is non-random for a hexagonal crystal system (fig. 3b).

Newly recrystallised grains have a contrasting but complementary texture. The pole figure data in figure (fig. 3a) shows a clear dispersion from the two dominant clusters documented for the relic grains. However, it is clear from the inverse pole figure colouring that grains retain an orientation that is close to the initial CPO of the relic grains. The misorientation histogram for newly recrystallised grains indicates that grain orientations are generally random but neighbouring grains retain lower relative misorientations (fig. 3b). 


\subsection{Spatial analysis of a representative microstructure}

The pair correlation function is used to understand the spatial distribution and relationship between syn-kinematic pores, newly recrystallised grains and relic grains. For this analyses a series of null hypotheses were defined. Broadly, these null hypotheses test the geological question, is the syn-kinematic porosity generated randomly?

More specifically, we define three individual null hypotheses to test the spatial configuration of 1) pores, 2) pores and newly recrystallised grains and 3) pores and relic grains. For each of these null hypothesis we generate 199 simulations of randomly distributed porosity. Additionally for the bivariant analyses, grains are fixed in space and the model of randomness considers the spatial randomness of pores with respect to fixed grains. The grey envelopes in each panel of figure 4 visualise the 5 th largest and smallest simulation of the 199 Monte Carlo simulations for the null hypotheses of each analysis.

\subsubsection{Spatial distribution of pores}

Here we employ the univariant pair correlation function. Using the null hypothesis that pores are randomly distributed in space we can see that the data does not conform to this model (fig. 4a). The analysis shows that data preferentially clusters at pair distances between 1 and $30 \mu \mathrm{m}$. There is also a weak divergence from the null model at approximately $43 \mu \mathrm{m}$. To better visualise the pair correlation result, figure $4 \mathrm{~d}$ shows an example pair distance between pore centres (e.g. blue line of $10 \mu \mathrm{m}$ ).

\subsubsection{The relationship between pores and newly recrystallised grains}

In this case, we employ the bivariant pair correlation function. The null hypothesis for randomness used here can be stated as: pores are randomly distributed in space with respect to newly recrystallised grains. In this analysis the data does not conform to the model of randomness (fig. 4b). Data is preferentially clustered at pair distances between 1 and $15 \mu \mathrm{m}$. Figure 4d shows an example of pair distances between pore centres and recrystallised grain centres (e.g. red line of $4 \mu \mathrm{m}$ ).

\subsubsection{The relationship between pores and relic grains}

To test this relationship we again use the bivariant pair correlation function. The modelled null hypothesis we test is that pores are randomly distributed in space with respect to relic grains. The results show that the data does conform to this model (fig. 4c). Pores and relic grains are randomly distributed in space with respect to one another.

\section{Interpretations and Discussion}

\subsection{Dynamic recrystallisation produces porosity}

Our microstructural textures document recrystallisation and, in line with the two original experimental studies conducted on Carrara marble at the conditions revisited (Pieri, Kunze, et al., 2001; Barnhoorn et al., 2004), we interpret the dominant mechanism to be sub-grain rotation recrystallisation (Bestmann \& Prior, 2003). Newly recrystallised grains preserve aspects of their parent grain's texture. We choose to interpret that an increased component of viscous grain boundary sliding allows for the randomisation of the parent grains texture (fig. 3). We claim that a consequence of this increase in viscous grain boundary sliding is the formation of creep cavities. The results presented in figure 4 ratify this interpretation by documenting that pores and recrystallised grains are clustered in space. Figure $4 \mathrm{~d}$ summarises the relationship documented by the pair correlation function. New pores are clustered in space and each pore is separated by distances approximately equal to the distribution of diameters of the recrystallised grain- 
a) Pores

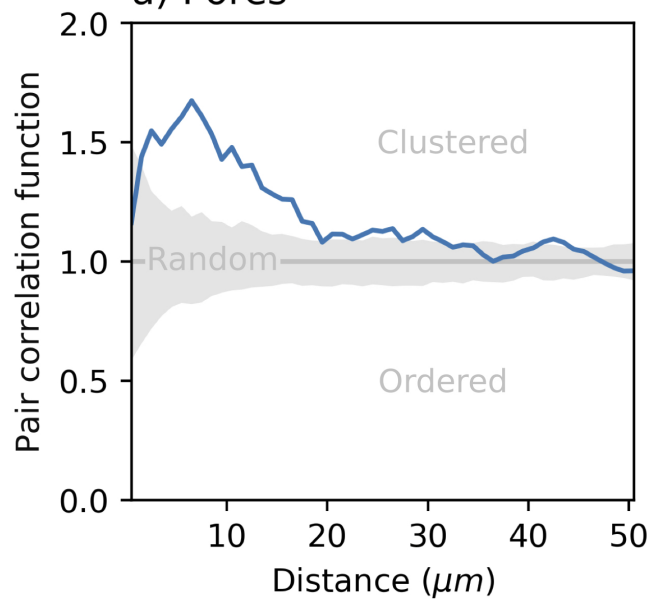

c) Relic vs pores

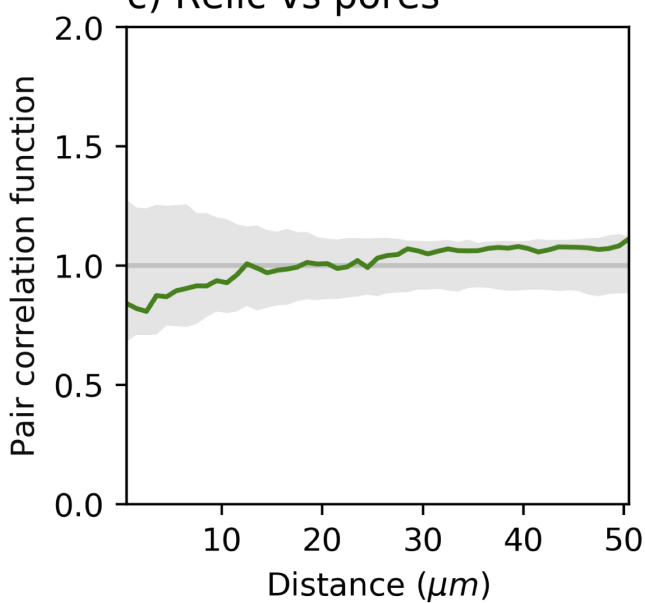

b) Recrystallised vs pores

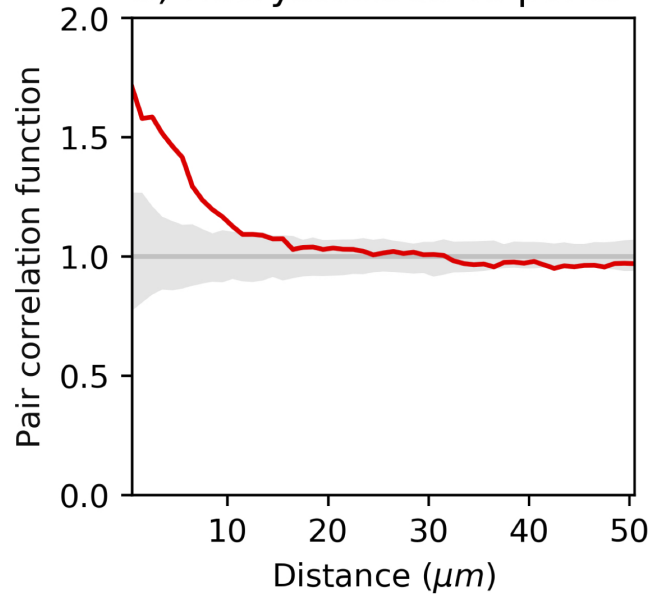

d)

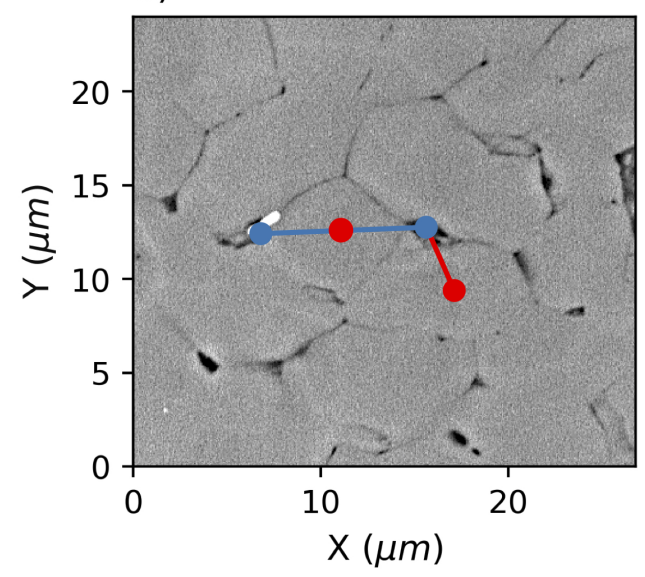

Figure 4. Spatial analysis of pores and grains. Figure 4a shows the univariant pair correlation analysis of pores, while figures $4 \mathrm{~b}$ and $\mathrm{c}$ show the bivariant analysis. As highlighted in figure 4a, data falling within the grey envelope shows a spatially random distribution, data with values greater than this indicate clustering and data less than the random window is spatially ordered. Figure $5 \mathrm{~d}$ summarises the results of figures $4 \mathrm{a}-\mathrm{c}$ in a schematic way. See the text for details. 
sizes (see example blue line in fig. 4d). While newly recrystallised grains are clustered in space with pores at distances roughly half of the diameter of the recrystallised grainsize (see example red line in fig. 4b). We suggest that the spatial relations of newly recrystallised grains and pores together with the EBSD data provide a statistical base to the assertion that creep cavities emerge with, and because of, sub-grain rotation recrystallisation.

\subsection{The Goetze criterion}

In the experiment we revisit the confining pressure $\left(P_{c}=300 \mathrm{MPa}\right)$ and the mean stress $\left(P_{m}=319 \mathrm{MPa}\right)$ are roughly 5.3 and 5.6 times larger than the peak differential stress $\left(\sigma_{\text {diff }}=57 \mathrm{MPa}\right)$ but despite this it is clear that dynamic recrystallisation produces an inter-granular porosity, creep cavities (fig. 1c and d). This is a significant experimental finding because it falsifies a common extension of the Goetze criterion; that pores, driven by creep, will not open, and remain so, during a deformation where the confining pressure is much larger than the differential stress (Evans \& Kohlstedt, 1995; Mei et al., 2010; Bercovici \& Skemer, 2017).

Our findings do show that the absolute porosity percentage generated is small $(\approx$ $0.1 \%$ (fig. 2a)), however its appearance is critically coupled with the process of dynamic recrystallisation. This is very important because the porosity is not generated randomly in space or time. The emergence of dynamic recrystallisation and creep cavitation can then be said to be a part of the collective dissipative response of the material to the imposed deformation. Critically, this suggests that creep cavitation is a fundamental and intrinsic thermo-mechanical dissipative process of a ductile fault rock. This interpretation, stated more plainly, emphasises that creep cavities are not an exotic feature of low pressure experiments or synthetic samples but are a necessary micro-mechanical feature of microstructural change during ductile creep.

This interpretation is not at odds with the Goetze criterion itself, which is a stress condition $\left(\sigma_{1}-\sigma_{3}=\sigma_{\text {diff }}=P\right.$; eq. 16 in Evans and Kohlstedt (1995)) that empirically defines the brittle-ductile transition. Namely, in the revisited experiment, the material has met its yield surface under the conditions of the Goetze criterion (more recently stated by (Mei et al., 2010) as; $\sigma_{d i f f}<P_{m}$ ). Importantly, the porosity phenomena described in our results is a function of the proceeding irreversible deformation. Therefore, while the magnitude of the principle stresses are an important initial condition for guaranteeing a ductile yielding, they do not predict the ultimate dissipative path of the material.

\subsection{Consequences for grain-size palaeopiezometery}

If creep cavitation is a fundamental process of ductile grain refinement, this raises several questions about the application of grain-size palaeopiezometry in monomineralic aggregates. Broadly, this form of palaeopiezometry is based on the widespread empirical experimental observation that for monomineralic aggregates the differential stress is inversely related to the average recrystallised grain or subgrain-size (see Twiss, 1977; Austin \& Evans, 2009; Hackl \& Renner, 2013, \& references therein). In detail, the empirical observation is explained by several authors differently but can generally be summaried to say that energetic gradients in the crystal lattice combined with grain surface energy drive the establishment of a steady state grain-size. The specifics of each model vary depending on which underyling recovery process is assumed to dominate but importantly the base of all of the models is the empirical observation. Critically, an implicit assumption in the all of the proposed theories of palaeopiezometry is that all grain-size change is isochoric (De Bresser et al., 1998) and solely related to the distortions and reorienting of the crystal lattice. Porosity driven by creep is precluded and therefore so is establishing grains by nucleation of new material in any dilatant sites. With the new 
results presented here we can state that the implicit assumption of grain-size palaeopiezometry in monomineralic aggregates may be incorrect.

Specifically, we have shown that pores do form with sub-grain rotation recrystallisation and have highlighted that at the very least second phases precipitate in the pores. While it remains an open question whether or not calcite has also nucleated in some of these sites, it is clear that pores allow for another path for a grain-size to be achieved. Our evidence and reasoning agrees well with recent work by Précigout and Stünitz (2016), where they interpreted that the olivine neoblasts nucleated and grew in creep cavities. They argued this in part from evidence that a population of smaller $(<1 \mu \mathrm{m})$ olivine grains appear well distributed in the recrystallised aggregate (see fig. 6 in Précigout and Stünitz (2016)). While Précigout and Stünitz (2016) do not provide direct evidence of creep cavities, our results would support their assumption. Additionally in high shear strain experiments on calcite-anhydrite mixtures, Cross and Skemer (2017) documented that calcite grains with more anhydrite than calcite neighbours (phase boundary fraction $>0.5)$ had smaller grains sizes than predicted by the palaeopiezometry. This observation may only reflect the competition of grain boundary surface energy and pinning processes of unlike phases but we would suggest it may highlight that the size of new grains is governed by nucleation and growth. Taken together these three sets of high shear strain experiments raise questions about where and when it would be valid to use grain-size palaeopiezometry. In particular, our results pose a problem for the ubiquitous use of grainsize palaeopiezometry in monomineralic domains of shear zones, like recrystallised quartz ribbons, because it may mean that one cannot easily know how many of the measured grains were in fact nucleated by precipitation rather than dynamically recrystallised. This difficulty is further emphasised by recent evidence from natural shear zones that creep cavities can form in monomineralic quartz aggregates (Gilgannon et al., 2017).

\subsection{Consequences for the paleowattmeter}

Our findings also have implications for the paleowattmeter (Austin \& Evans, 2009) but they may be less problematic because its steady state grain-size is derived from a rate of work equation. Fundamentally, the paleowattmeter proposes that a steady state grain-size stabilises when there is a balance between the rate of grain-size reduction, driven by the power stored in the microstructre from creep, and growth processes, driven by the minimisation of surface energy. More abstractly, the equations used to formulate the paleowattmeter are based on the notion of stored and dissipated energy which would allow the method to remain valid if the number of dissipative mechanisms was increased to include creep cavitation. Additionally, the grain growth equation would need to be expanded to include some knowledge of second phases. This could be achieved through the integration of the Zener parameter as proposed by Herwegh et al. (2011). The exact implementation of either of these points is not trivial as it would probably require considerable assumption about the partitioning of dissipation or experimental constraints on the energetics of creep cavitation at the scale of a sample.

\subsection{A path from single phase to polyphase}

While the sample we investigated is considered to be nominally pure, it is clear that minor phases are present and mass is being transported during deformation (see fig. 1c and d). It is unclear over what distances mass is transported but it is apparent that the creep cavities play a role in providing sites of precipitation. The most significant consequence of this is that, without the aid of chemical reaction or fracture, a monomineralic ductile material has a fundamental and spontaneous path to transition to a second phase controlled microstructure and ultimately a polymineralic aggregate.

Our results experimentally corroborate the conceptual model of Linckens et al. (2015) for ophiolites, where they suggest that a second phase controlled microstructures could 
arise out of a combination of dynamic recrystallisation and grain boundary sliding. Furthermore, our results build out the older models of granular flow from Herwegh and Jenni (2001) in carbonate shear zones, and more generally the model for mature polyphase shear zones of Fusseis et al. (2009). In both cases the nucleation of material occurs, in part, because of the production of syn-kinematic pores. The biggest implication of making the association with Fusseis et al. (2009) is that we suggest the cavities act as part of a dynamic permeability. Despite the excellent quality of both the experimental and microstructural data presented here, we cannot unambiguously show this in our study. That being said, our work probably showcases one way that a thoroughly mixed polyphase ultramylonite can form and points towards important future research questions that involve creep cavities. In particular: (1) in more chemically complex rocks, does the coupling of chemistry and mechanics lead to efficient filling of pores?; and (2) if not what does this open porosity mean for fault rock stability? We propose that clearly demonstrating the true dynamic action of the so called dynamic granular fluid pump of Fusseis et al. (2009) is one of the next great challenges of our community.

\section{Conclusions and outlook}

In experiments designed to understand the steady state deformation of deep shear zones, we have documented that creep cavities emerge with grain-size reduction by subgrain rotation recrystallisation. This is an important finding because it shows that creep driven porosity can be opened and sustained in rocks at a high confining pressure. More than this, our results suggest that the transformation of an undeformed monomineralic rock into an ultramylonite should be accompanied by syn-kinematic pore formation. A direct outcome of this is that, if material is available to precipitate into pores, phase mixtures can form spontaneously from the deformation of single phase rocks. The most provocative extension our results is that, if pores remain open, ductile shear zones may necessarily develop hydro-mechanical anisotropy with ultramylonites providing sites of mechanical instability. More generally, our results challenge the use of grain-size palaeopiezometers to estimate stress in mylonites as they rely on the assumption that monomineralic domains are not affected by precipitation processes.

\section{Acknowledgments}

This work was financially supported by the Swiss National Science Foundation (SNSF; grant number 162340). We would like to thank Christoph Neururer and Bernard Grobéty for both their help and the use of their SEM at Fribourg University. James Gilgannon would like to thank Alba Zappone for her help in searching through the rock samples of ETHZ and Marius Waldvogel for many discussion that helped shape this contribution. Supplementary information Datasets can be obtained from the Bern Open Repository and Information System (BORIS) under the BORIS doi:10.7892/boris.134751. We thank Christian Huber for his role as editor and Alexandre Dimanov, Phil Skemer and two anonymous reviewers for their constructive and thorough reviews.

\section{References}

Akker, I., Kaufmann, J., Desbois, G., Klaver, J., Urai, J., Berger, A., \& Herwegh, M. (2018). Multiscale porosity changes along the pro- and retrograde deformation path: an example from alpine slates. Solid Earth, 9(5), 1141-1156. doi: https://doi.org/10.5194/se-9-1141-2018

Austin, N., \& Evans, B. (2009). The kinetics of microstructural evolution during deformation of calcite. Journal of Geophysical Research: Solid Earth, 114(B9). doi: https://doi.org/10.1029/2008JB006138

Barnhoorn, A., Bystricky, M., Burlini, L., \& Kunze, K. (2004). The role of recrys- 
tallisation on the deformation behaviour of calcite rocks: large strain torsion experiments on carrara marble. Journal of Structural Geology, 26(5), 885 903. doi: https://doi.org/10.1016/j.jsg.2003.11.024

Bercovici, D., \& Skemer, P. (2017). Grain damage, phase mixing and plate-boundary formation. Journal of Geodynamics, 108, 40 - 55. doi: https://doi.org/10 .1016/j.jog.2017.05.002

Bestmann, M., \& Prior, D. (2003). Intragranular dynamic recrystallization in naturally deformed calcite marble: diffusion accommodated grain boundary sliding as a result of subgrain rotation recrystallization. Journal of Structural Geology, 25(10), 1597 - 1613. doi: https://doi.org/10.1016/S0191-8141(03)00006-3

Ceccato, A., Menegon, L., Pennacchioni, G., \& Morales, L. (2018). Myrmekite and strain weakening in granitoid mylonites. Solid Earth, 9(6), 1399-1419. doi: https://doi.org/10.5194/se-9-1399-2018

Cross, A. J., \& Skemer, P. (2017). Ultramylonite generation via phase mixing in high-strain experiments. Journal of Geophysical Research: Solid Earth, 122(3), 1744-1759. doi: https://doi.org/10.1002/2016JB013801

De Bresser, J., Peach, C., Reijs, J., \& Spiers, C. (1998). On dynamic recrystallization during solid state flow: Effects of stress and temperature. Geophysical Research Letters, 25 (18), 3457-3460. doi: https://doi.org/10.1029/98GL02690

Dimanov, A., Rybacki, E., Wirth, R., \& Dresen, G. (2007). Creep and straindependent microstructures of synthetic anorthite-diopside aggregates. Journal of Structural Geology, 29(6), 1049 - 1069 . doi: https://doi.org/10.1016/ j.jsg.2007.02.010

Evans, B., \& Kohlstedt, D. (1995). Rheology of rocks. In Rock physics \& phase relations (p. 148-165). American Geophysical Union (AGU). doi: https://doi.org/ 10.1029/RF003p0148

Fusseis, F., Regenauer-Lieb, K., Liu, J., Hough, R. M., \& De Carlo, F. (2009). Creep cavitation can establish a dynamic granular fluid pump in ductile shear zones. Nature, 459, 974977. doi: https://doi.org/10.1038/nature08051

Gilgannon, J., Fusseis, F., Menegon, L., Regenauer-Lieb, K., \& Buckman, J. (2017). Hierarchical creep cavity formation in an ultramylonite and implications for phase mixing. Solid Earth, 8(6), 1193-1209. doi: 10.5194/se-8-1193-2017

Hackl, K., \& Renner, J. (2013). High-temperature deformation and recrystallization: A variational analysis and its application to olivine aggregates. Journal of Geophysical Research: Solid Earth, 118(3), 943-967. doi: https://doi.org/10 $.1002 /$ jgrb.50125

Herwegh, M., \& Jenni, A. (2001). Granular flow in polymineralic rocks bearing sheet silicates: new evidence from natural examples. Tectonophysics, 332(3), 309 320. doi: https://doi.org/10.1016/S0040-1951(00)00288-2

Herwegh, M., Linckens, A., J.and Ebert, Berger, A., \& Brodhag, S. (2011). The role of second phases for controlling microstructural evolution in polymineralic rocks: A review. Journal of Structural Geology, 33(12), 1728 - 1750. doi: https://doi.org/10.1016/j.jsg.2011.08.011

Hill, R. (1963). Elastic properties of reinforced solids: Some theoretical principles. Journal of the Mechanics and Physics of Solids, $11(5), 357$ - 372. doi: https:// doi.org/10.1016/0022-5096(63)90036-X

Hirth, G., \& Tullis, J. (1992). Dislocation creep regimes in quartz aggregates. Journal of Structural Geology, 14(2), 145 - 159. doi: https://doi.org/10.1016/0191 -8141(92)90053-Y

Kruse, R., Stünitz, H., \& Kunze, K. (2001). Dynamic recrystallization processes in plagioclase porphyroclasts. Journal of Structural Geology, 23(11), 1781 - 1802. doi: https://doi.org/10.1016/S0191-8141(01)00030-X

Lee, K.-H., Jiang, Z., \& Karato, S.-I. (2002). A scanning electron microscope study of the effects of dynamic recrystallization on lattice preferred orientation in olivine. Tectonophysics, 351 (4), 331 - 341. doi: https://doi.org/10.1016/ 
Linckens, J., Herwegh, M., \& Müntener, O. (2015). Small quantity but large effect how minor phases control strain localization in upper mantle shear zones. Tectonophysics, 643, 26 - 43. doi: https://doi.org/10.1016/j.tecto.2014.12.008

Lopez-Sanchez, M. A., \& Llana-Fúnez, S. (2018). A cavitation-seal mechanism for ultramylonite formation in quartzofeldspathic rocks within the semibrittle field (vivero fault, nw spain). Tectonophysics, 745, 132 - $153 . \quad$ doi: https://doi.org/10.1016/j.tecto.2018.07.026

Mei, S., Suzuki, A., Kohlstedt, D., Dixon, N., \& Durham, W. (2010). Experimental constraints on the strength of the lithospheric mantle. Journal of Geophysical Research: Solid Earth, 115(B8). doi: https://doi.org/10.1029/2009JB006873

Menegon, L., Fusseis, F., Stünitz, H., \& Xiao, X. (2015, 03). Creep cavitation bands control porosity and fluid flow in lower crustal shear zones. Geology, 43(3), 227-230. doi: https://doi.org/10.1130/G36307.1

Menegon, L., Stünitz, H., Nasipuri, P., Heilbronner, R., \& Svahnberg, H. Transition from fracturing to viscous flow in granulite facies perthitic feldspar (lofoten, norway). Journal of Structural Geology, 48, 95-112. doi: https://doi.org/10.1016/j.jsg.2012.12.004

Michibayashi, K., Ina, T., \& Kanagawa, K. (2006). The effect of dynamic recrystallization on olivine fabric and seismic anisotropy: Insight from a ductile shear zone, oman ophiolite. Earth and Planetary Science Letters, 244 (3), 695 - 708. doi: https://doi.org/10.1016/j.epsl.2006.02.019

Mitchell, E., Kenchington, C., Liu, A., Matthews, J., \& Butterfield, N. (2015). Reconstructing the reproductive mode of an ediacaran macro-organism. Nature, 524, 343 EP -. doi: https://doi.org/10.1038/nature14646

Paterson, M., \& Olgaard, D. (2000). Rock deformation tests to large shear strains in torsion. Journal of Structural Geology, 22(9), 1341 - 1358. doi: https://doi .org/10.1016/S0191-8141(00)00042-0

Pieri, M., Burlini, L., Kunze, K., Stretton, I., \& Olgaard, D. (2001). Rheological and microstructural evolution of carrara marble with high shear strain: results from high temperature torsion experiments. Journal of Structural Geology, 23(9), 1393 - 1413. doi: https://doi.org/10.1016/S0191-8141(01)00006-2

Pieri, M., Kunze, K., Burlini, L., Stretton, I., Olgaard, D., Burg, J.-P., \& Wenk, H.-R. (2001). Texture development of calcite by deformation and dynamic recrystallization at $1000 \mathrm{k}$ during torsion experiments of marble to large strains. Tectonophysics, 330(1), 119 - 140. doi: https://doi.org/10.1016/ S0040-1951(00)00225-0

Précigout, J., Prigent, C., Palasse, L., \& Pochon, A. (2017). Water pumping in mantle shear zones. Nature Communications, 8(1), 15736. doi: https://doi.org/10 $.1038 /$ ncomms 15736

Précigout, J., \& Stünitz, H. (2016). Evidence of phase nucleation during olivine diffusion creep: A new perspective for mantle strain localisation. Earth and Planetary Science Letters, 455, 94 - 105. doi: https://doi.org/10.1016/j.epsl.2016 .09 .029

Précigout, J., Stünitz, H., \& Villeneuve, J. (2019). Excess water storage induced by viscous strain localization during high-pressure shear experiment. Scientific Reports, 9(1), 3463. doi: https://doi.org/10.1038/s41598-019-40020-y

Regenauer-Lieb, K., Karrech, A., Chua, H., Poulet, T., Veveakis, M., Wellmann, F., ... Lester, D. (2014). Entropic bounds for multi-scale and multi-physics coupling in earth sciences. In Beyond the second law: Entropy production and non-equilibrium systems (pp. 323-335). Berlin, Heidelberg: Springer Berlin Heidelberg. doi: https://doi.org/10.1007/978-3-642-40154-1_17

Stipp, M., Stünitz, H., Heilbronner, R., \& Schmid, S. (2002). The eastern tonale fault zone: a natural laboratory for crystal plastic deformation of quartz over a temperature range from 250 to 700c. Journal of Structural Geology, 24(12), 
1861 - 1884. doi: https://doi.org/10.1016/S0191-8141(02)00035-4

Ter Heege, J., De Bresser, J., \& Spiers, C. (2002). The influence of dynamic recrystallization on the grain size distribution and rheological behaviour of carrara marble deformed in axial compression. Geological Society, London, Special Publications, 200(1), 331-353. doi: https://doi.org/10.1144/ GSL.SP.2001.200.01.19

Tullis, J., \& Yund, R. (1985, 04). Dynamic recrystallization of feldspar: A mechanism for ductile shear zone formation. Geology, 13(4), 238-241. doi: https:// doi.org/10.1130/0091-7613(1985)13〈238:DROFAM $\rangle 2.0 . C O ; 2$

Twiss, R. J. (1977). Theory and applicability of a recrystallized grain size paleopiezometer. In Stress in the earth (pp. 227-244). Basel: Birkhäuser Basel. doi: https://doi.org/10.1007/978-3-0348-5745-1_13

Wiegand, T., Martínez, I., \& Huth, A. (2009). Recruitment in tropical tree species: Revealing complex spatial patterns. The American Naturalist, 174(4), E106E140. doi: https://doi.org/10.1086/605368

Wiegand, T., \& Moloney, K. (2014). Handbook of spatial point-pattern analysis in ecology. Boca Raton, FL: Chapman and Hall/CRC. 